\title{
Efficacy of Mangrove (Rhizophora Mucronata) Roots Powder in Adsorption of Lead (II) Ions from Aqueous Solutions: Equilibrium and Kinetics Studies
}

\author{
Fidelis Ngugi, John Mmari Onyari and John Namakwa Wabomba \\ School of Physical Sciences, College of Biological and Physical Sciences, University of Nairobi, \\ P.O. Box 30197- 0100, Nairobi, Kenya
}

\begin{abstract}
The removal of $\mathrm{Pb}$ (II) ions by adsorption onto mangrove roots adsorbent was investigated in this present paper. The removal of lead ions from aqueous solutions was investigated in batch mode which involved the study of the effects of initial $\mathrm{pH}$, temperature, initial concentration of the lead ion, adsorbent dosage and contact time on lead ions removal. Adsorption was found to increase with increase in temperature, contact time adsorbent dose and $\mathrm{pH}$. The adsorption data was well described by both the Freundlich and Langmuir isotherm models. The adsorption capacity $\left(Q_{\max }\right)$ from the Langmuir isotherm for $\mathrm{Pb}(\mathrm{II})$ was found to be $13.698 \mathrm{mg} / \mathrm{g}$. Pseudo-second order kinetic model was found suitable for describing the kinetics of the adsorption process. These results indicated that mangrove roots can be used as low cost adsorbent for the removal of lead ions from aqueous solutions.
\end{abstract}

Keywords: Adsorption, Batch mode, Mangroves and Kinetics.

\section{Introduction}

Excessive release of heavy metals into the environment due to industrialization and urbanization has posed a great problem worldwide [1]. Unlike organic pollutants, the majority of which are susceptible to biological degradation, heavy metal ions like chromium, lead, arsenic copper, cadmium and nickel do not degrade into harmless end products [2]. Heavy metal contamination exists in aqueous wastes of many industries, such as metal plating, mining operations, tanneries, radiator manufacturing, smelting, alloy industries and storage batteries industries.

Lead is an element of concern because of its ability to bio-magnify, bio-accumulate and its high toxicity even at low concentrations [3]. Generally, lead has been reported to cause renal dysfunction, hypertension, lung complications and bone lesions [4] Further, exposure to lead may result in, autism, psychosis, allergies, dyslexia, hyperactivity, paralysis and even death [5].

Studies by [6] and [7] shows that treated wastewater is a major component of water resources required for addressing the needs of a growing economy. However, the greatest challenge in wastewater treatment is the adoption of low cost wastewater treatment technologies that maximizes the efficiency of wastewater treatment while ensuring compliance with health and safety standards [8]. The commonly used processes in wastewater treatment include coagulation, filtration with coagulation, precipitation, ozonation, adsorption, ion exchange, reverse osmosis and advanced oxidation [4].These processes have serious limitations which include; being costly, inefficient in removing pollutants and, generation of more sludge posing a problem in terms of disposal [9].

Studies on the treatment of effluent bearing heavy metal have revealed adsorption to be a highly effective technique for the removal of heavy metal from waste water and activated carbon has been widely used as an adsorbent. Despite its extensive use in the water and wastewater treatment, activated carbon remains an expensive material. In recent years, the need for ecofriendly and economical materials for the elimination of heavy metals from contaminated waters has necessitated research interest towards the production of low cost alternatives to commercially available activated carbon.

Mangroves are woody plants that grow in the inter-tidal areas between land and sea in the tropic and subtropical latitudes [10]. Mangroves are unique plants because of their ability to concentrate pollutants such as toxic chemicals, metal ions, pesticides and herbicides [11].Mangroves have also been used for phytoremediation of heavy metal pollution, thus earning a reputation of being a sink for heavy metals [12]. Therefore, the current study will utilize mangrove roots from Kenyan Coast as the appropriate adsorbent for the removal of lead from aqueous solutions. 


\subsection{Mangrove roots collection and preparation}

\section{Materials and Methods}

Mangrove roots were collected from Dongo Kundu in Mombasa County, Kenya. The roots samples were washed with distilled water to remove soil and soluble particles. Cleaned roots samples were then oven dried at $80{ }^{\circ} \mathrm{C}$ for 24 hours in order to obtain biomass in completely dried form. The dried mangrove samples were then ground into fine powder using mechanical grinder after which the powder was soaked and washed severally with both cold and hot tap water until clean. Cleaned mangrove roots powder was then soaked for 24 hours in cold distilled water, washed thoroughly and then dried in an oven at $80{ }^{0} \mathrm{C}$ for 24 hours. Dried roots sample were finally sieved into different particle sizes of $<300 \mu \mathrm{m},>300<425 \mu \mathrm{m}$ and $>425 \mu \mathrm{m}$ and stored in plastic containers awaiting adsorption experiments.

\subsection{Reagents}

All reagents used were of analytical grade. Stock solutions of $1000 \mathrm{mg} / \mathrm{L}$ were prepared by dissolving $1.6066 \mathrm{~g}$ of lead (II) nitrate in double distilled water. Working solutions of lead (II) nitrate were prepared by appropriate dilutions of stock solutions. Adjustments of $\mathrm{pH}$ were made using $0.1 \mathrm{M}$ hydrochloric acid and $0.1 \mathrm{M}$ sodium hydroxide. Sodium hydroxide $(0.1 \mathrm{M})$ solution was prepared by dissolving $4.0 \mathrm{~g}$ in double distilled water while hydrochloric acid $(0.1 \mathrm{M})$ solution was made by dissolving an appropriate amount of $12 \mathrm{M}$ concentrated acid (Aldrich Company) in double distilled de-ionized water.

\subsection{Instrumentation}

All pH measurements were made using Exstik II EC $250 \mathrm{pH} /$ conductivity/TDS meter. A test sieve (Retsch 5657) was used to separate the ground sample into different sizes. A thermometer and an incubator (model Gallenkamp orbital incubator) were also used to monitor the effect of temperature on the adsorption. Solutions were constantly agitated using an orbital shaker (Maximix Type 65800, Thermolyne) for all the experiments except the experiment involving temperature where the Gallenkamp orbital incubator was equipped with a shaker. Gravity filtration was done through micro filter with 0.47 um pore size and a stop watch was also used to monitor time. A mechanical grinder was used for grinding while an analytical balance (Fisher scientific A 160) was used for all weight measurements. Residual and initial concentrations of lead ions were determined using atomic absorption spectrophotometer (CTA 2000 AAS). Volumetric flasks (1000, 2000, 500, 250, 100, 50,25 and $10 \mathrm{~mL}$ ) were used in preparations and dilutions of the solutions while propylene bottles were used for conducting the experiments.

\subsection{Batch Adsorption Experiments}

Batch experiments were conducted using $60 \mathrm{ml}$ propylene bottles to which metal ions solution and biomass were added. These bottles were agitated in an orbital shaker at a constant speed of $200 \mathrm{rpm}$ to study the effect of parameters such as $\mathrm{pH}$, adsorbent dosage, initial lead ion concentration, contact time and temperature. Samples were withdrawn at appropriate time intervals and filtered. The filtrates were used for analysis of the residual lead ions concentration using an atomic absorption spectrophotometer (AAS). The percentage of lead ions removed was calculated from the differences between the initial $\left(C_{0}\right)$ and equilibrium $\left(C_{\mathrm{e}}\right)$ lead (II) ions concentration which is given by the equation.

$$
\% \text { Removal }=\frac{C_{0-} C_{e}}{C_{0}} \times 100
$$

In order to determine optimum adsorption (i.e. amount of lead ion adsorbed per unit mass of mangrove roots), $30 \mathrm{~mL}$ portions of lead solutions were dosed with different amounts of mangrove roots biomass and placed on an orbital shaker set at a predetermined speed and for predetermined equilibration time. The kinetics of adsorption was determined by analyzing adsorptive uptake of lead ions from the aqueous solutions at different time intervals. Adsorption isotherms were also computed using adsorption data obtained when different metal ion concentrations were used on fixed amounts of mangrove biomass at equilibrium.

\subsection{Adsorption Isotherm Models}

Batch Adsorption isotherms for lead ions by mangroves roots were expressed in terms of Langmuir and Freundlich adsorption models. The Langmuir model assumes a monolayer adsorption of solutes onto a surface comprised of a finite number of identical sites with homogeneous adsorption energy [3].

This model is expressed as follows: 


$$
\left.\frac{C_{e}}{q_{e}}=\frac{1}{Q_{\max } b}+\frac{1}{Q_{\max }} C_{e} \quad \text { (linear form }\right)
$$

Where: $q_{\mathrm{e}}$ is the amount of solute adsorbed per unit weight of adsorbent $(\mathrm{mg} / \mathrm{g}), C_{\mathrm{e}}$ the equilibrium concentration of solute in the bulk solution $\left(\mathrm{mgL}^{-1}\right), Q_{\max }$ the monolayer adsorption capacity $\left(\mathrm{mgg}^{-1}\right)$ and $b$ is the Langmuir constant which reflects the binding strength between metal ions and adsorbent surface $\left(\mathrm{Lmg}^{-1}\right)$. The Freundlich isotherm is an empirical expression that takes into account the heterogeneity of the surface and multilayer adsorption to the binding sites located on the surface of the adsorbent. The Freundlich model is expressed as follows

$$
\log q_{e}=K_{F}+\frac{1}{n} \log C_{e} \text { (linear form) }
$$

Where: $q_{\mathrm{e}}$ is the amount of solute adsorbed per unit weight of adsorbent $\left(\mathrm{mgg}^{-1}\right), C_{\mathrm{e}}$ the equilibrium concentration of solute in the bulk solution $\left(\mathrm{mgL}^{-1}\right), K_{\mathrm{F}}$ a constant indicative of the relative adsorption capacity of the adsorbent $\left(\mathrm{mgg}^{-1}\right)$ and the constant $1 / n$ indicates the intensity of the adsorption. $n$ is considered as the heterogeneity of the adsorbate and its affinity for the adsorbent.

\subsection{Adsorption kinetic studies}

The kinetics of lead metal adsorption onto the mangrove roots biomass was predicted using pseudofirst-order and pseudo-second-order models. Pseudo-first-order model is used to describe the reversibility of the equilibrium between solid and liquid phases [13]. The model also assumes that the metal cation binds only on one sorption site on the sorbent surface. The pseudo-first-order model is expressed by the equation shown below.

$$
\log \left(q_{e}-q_{t}\right)=\log c_{e}-\frac{K_{1}}{2.303} t
$$

Where: $\mathrm{q}_{\mathrm{e}}$ and $\mathrm{q}_{\mathrm{t}}$ are the amounts of heavy metal adsorbed $\left(\mathrm{mg} \mathrm{g}^{-1}\right)$ at equilibrium and at the time (t $\min )$ and $k_{1}$ is the rate constant of the pseudo-first-order adsorption process $\left(\mathrm{min}^{-1}\right)$. Linear plots of $\log \left(\mathrm{q}_{\mathrm{e}}-\mathrm{q}_{\mathrm{t}}\right)$ versus $\mathrm{t}$ are used to predict the rate constant $\left(\mathrm{k}_{1}\right)$ and adsorption at equilibrium $\left(\mathrm{mg} \mathrm{g}^{-1}\right)$, which are obtained from the slope and intercept respectively. The pseudo-second-order equation assumes that the rate limiting step might be due to chemical adsorption. According to this model, metal cations can bind to two binding sites on the adsorbent surface. The equation can be expressed as shown below.

$$
\frac{t}{q_{t}}=\frac{1}{k_{2} q_{e}^{2}}+\frac{1}{q_{e}} t
$$

Where: $\mathrm{k}_{2}$ is the rate constant of the pseudo-second-order adsorption $\left(\mathrm{gmg}^{-1} \mathrm{~min}^{-1}\right)$. If the adsorption kinetics obeys the pseudo-second-order model, a linear plot of $t / q_{t}$ versus $t$ can be observed. The slope of the plot will give the value of calculated adsorption at equilibrium $\left(\mathrm{q}_{\mathrm{e}} \mathrm{calc}\right)$, while the intercept gives the value of the rate constant $\left(\mathrm{k}_{2}\right)$.

\section{Results and Discussions}

\subsection{Effect of equilibration time and initial concentration on adsorption of $P b$ (II) ions}

The percentage of lead adsorbed at varying contact time keeping other parameters constant is presented in Fig. 1 below. According to the Figure, at lower initial $\mathrm{Pb}$ (II) ion concentration (50 ppm) the \% adsorption was very high even attaining the $96 \%$ mark within 5 minutes of contact time. At high concentration of 1000 ppm, a reduced adsorption (69\%) was observed within the same contact time of 5 minutes, and even after the set 55 minutes $(81.7 \%)$. This implied that upon contact of the biomass with the lead ions, the metal ions were rapidly taken up by the mangrove roots biomass. 


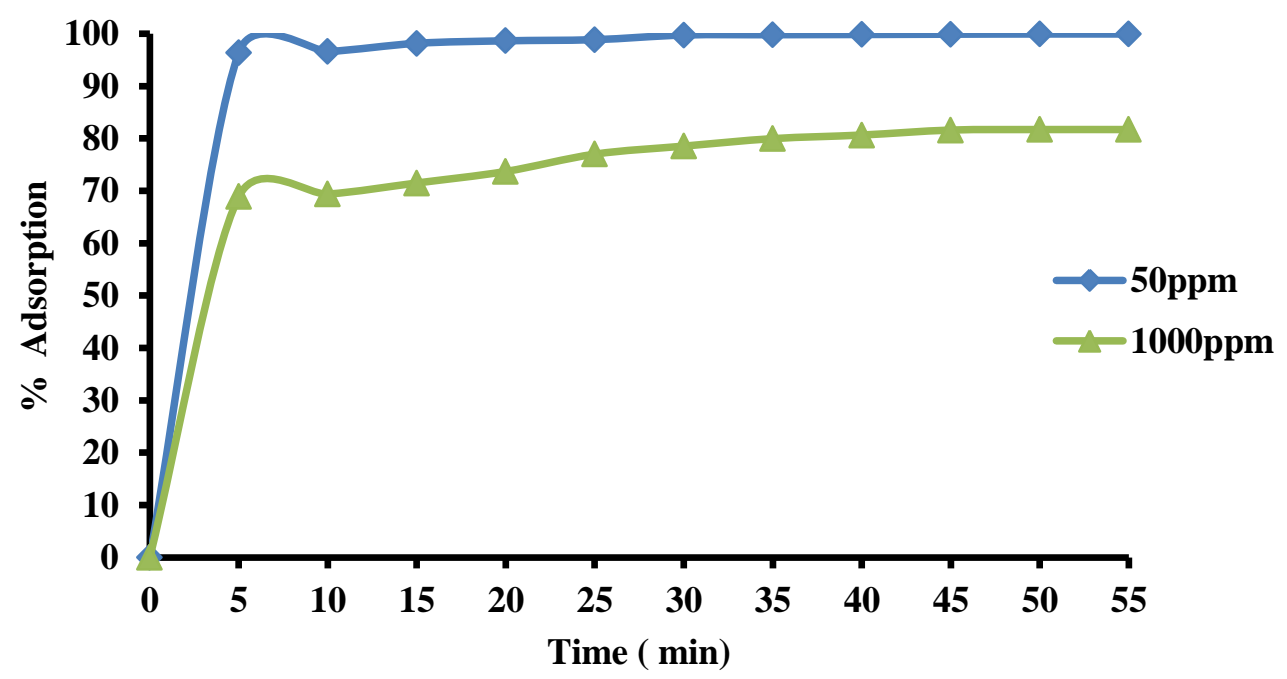

Figure 1: Effect of contact time and concentration on \% adsorption of $\mathrm{Pb}$ (II) ions by $0.5 \mathrm{~g}$ mangrove roots.

As shown in Fig. 1, adsorption increased rapidly with time and then reached a point where there was no change in adsorption with increase in contact time. The initial fast adsorption could be explained also through physical adsorption since adsorption phenomenon characteristically tends to attain instantaneous equilibrium. The number of active sites in the system was fixed and each active site could adsorb only one ion in a monolayer therefore metal uptake by the sorbent surface was rapid initially and then decreased as the availability of active sites decreased thus slowing down the transfer of metal ion from solution to the adsorbent surface. [14] stated that adsorption sites at equilibrium are saturated; therefore cannot adsorb any more of the metal ions. [15] reported that removal of $\mathrm{Cr}(\mathrm{VI})$ ions from aqueous solution using activated carbon increased with contact time and obtained a saturation point at 90 minutes.

\subsection{Effect of weight of adsorbent and particle size on adsorption of $\mathrm{Pb}$ (II) ions.}

The effect of particle size of mangrove roots on removal of $\mathrm{Pb}$ (II) ions was studied using three different sizes $(\leq 300 \mu \mathrm{m}, \geq 300 \leq 425 \mu \mathrm{m}$ and $\geq 425 \mu \mathrm{m})$. Fig. 2 shows the percentage removal of $\mathrm{Pb}^{2+}$ ions from aqueous solutions as a function of weight of mangrove roots of three different sizes.

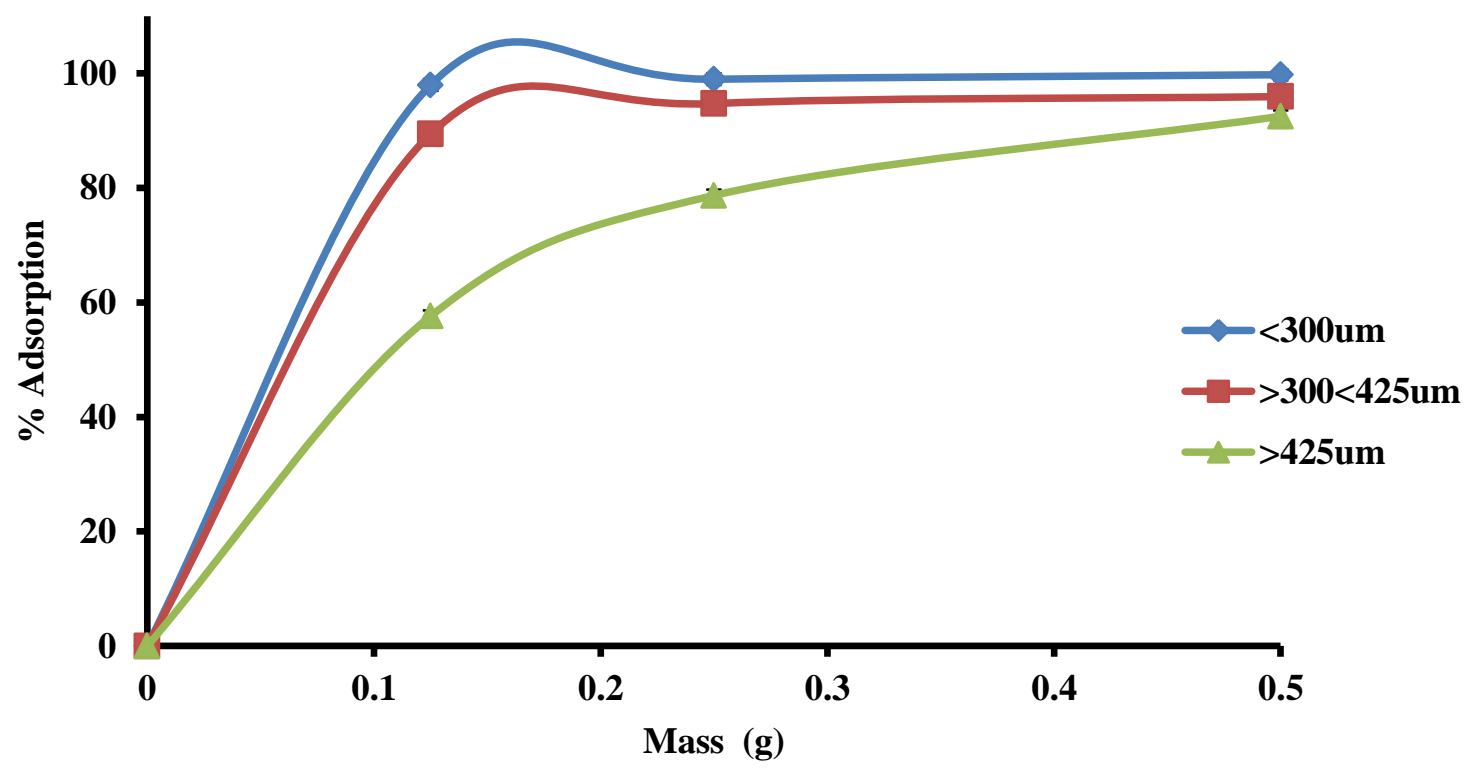

Figure 2: Effect of weight and particle size of mangrove roots on adsorption of $50 \mathrm{ppm} \mathrm{Pb}$ (II) ions. 
From Fig. 2, it is evident that there was an increase in the \% adsorption with increase in mass for all the particle sizes. The increase in the adsorption was due to the availability of more binding sites for metal ions. The decrease in particle size also had an influence of increasing the \% adsorption as the particle size decreased. The smallest particle size i.e., $\leq 300 \mu \mathrm{m}$ gave the highest $\%$ adsorption. The smaller the particle size, the larger the surface area exposed to interact with the metal ions in solution. This reaffirms the fact that adsorption takes place via surface mechanism. Increase in surface area meant more binding sites were in contact with the adsorbate. The increase in particle size had a reverse effect of decreasing surface area, reducing number of binding sites hence decreasing the \% adsorption.

Similar results were observed by [16] who worked on rice husks and [17] who worked on treated sawdust of sissoo wood. [18] demonstrated that the adsorption of $\mathrm{Pb}$ (II) ions increased linearly as the amount of adsorbent (mixture of activated charcoal and peanut shell) increased from $1.0 \mathrm{~g}$ to $3.0 \mathrm{~g}$ and became constant from $3.0 \mathrm{~g}$ to $5.0 \mathrm{~g}$.

\subsection{Effect of initial concentration of $P b$ (II) ions on adsorption}

The rate of adsorption is a function of initial concentration of metal ions which makes concentration an important factor to be considered for effective adsorption [19]. The experimental data illustrating the effect of initial metal ion concentration on the rate of adsorption of $\mathrm{Pb}$ (II) ions onto the mangrove roots biomass is presented in Fig. 3.

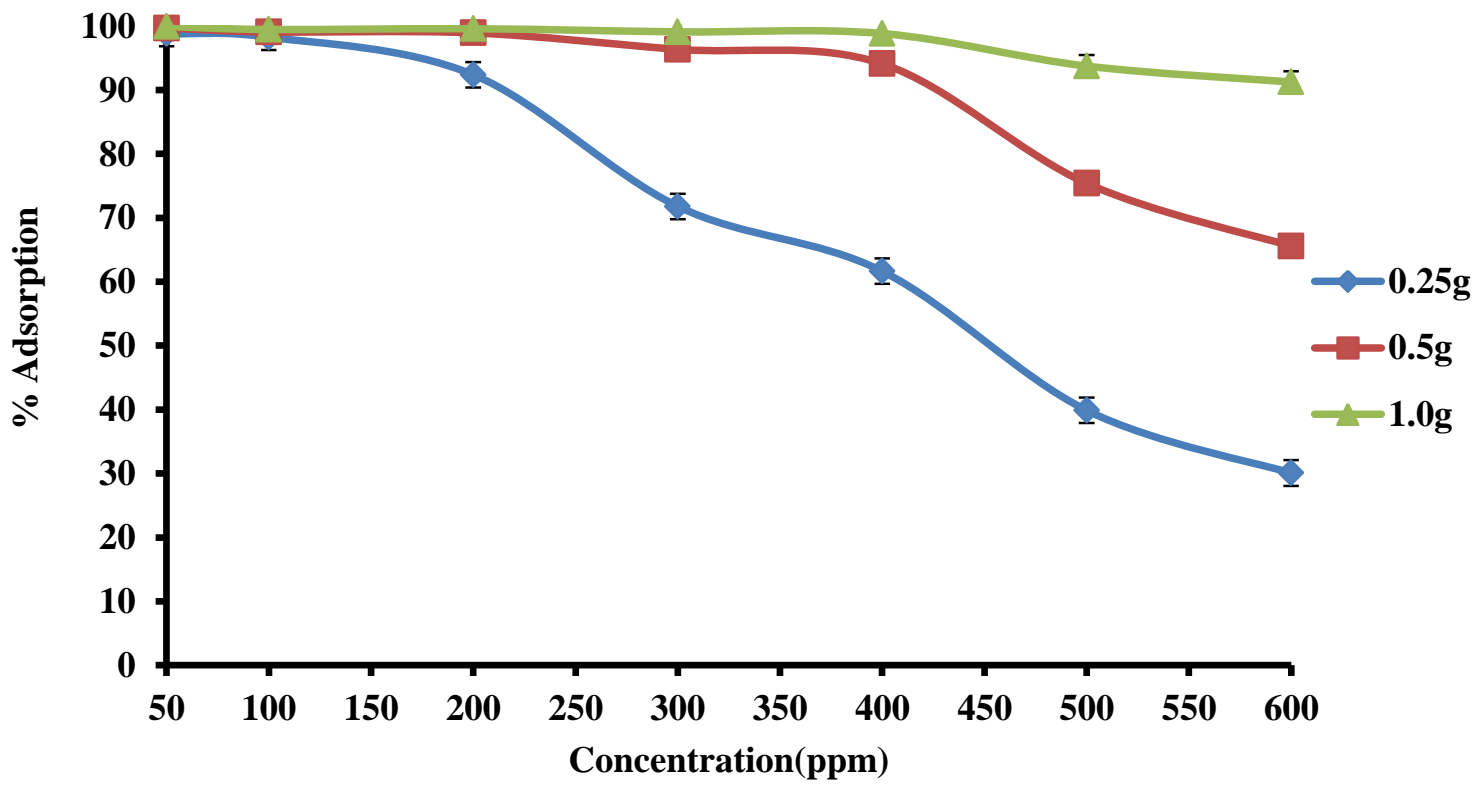

Figure 3: Effect of initial concentration of $\mathrm{Pb}$ (II) ions on adsorption mangrove roots

When the initial metal ion concentration was increased from 50 to $100 \mathrm{ppm}$ the $\%$ adsorption was almost the same $(100 \%)$ for all the masses. However, as the concentration changed from 100 to $600 \mathrm{ppm}$ the $\%$ adsorption decreased from $99 \%$ to $91.2 \%, 65.6 \%$ and $30 \%$ for $1.0 \mathrm{~g}, 0.5 \mathrm{~g}$ and $0.25 \mathrm{~g}$ respectively. When the initial concentrations was increased the $\%$ adsorption of the $\mathrm{Pb}$ (II) ions decreased.

This could be due to saturation of the active adsorption sites on the mangrove roots at higher concentrations. Metal ions need to migrate to the biomass surface by intra-particle diffusion and greatly hydrolyzed ions diffused at a slower rate [20], these accounts for the reduction in the percentage adsorption. It can also be seen that an increase in the amount of the mangroves biomass led to an increase in the \% adsorption. This could probably be due to the ratio of mass of adsorbent to concentration of the adsorbate. Similar results have been observed by [21], [22] and [23].

\subsection{Effect of temperature on $\mathrm{Pb}$ (II) ions adsorption}

To determine the effect of temperature, experiments were carried out by varying temperatures from 25 to $70^{\circ} \mathrm{C}$. The results are shown in Fig. 4. 


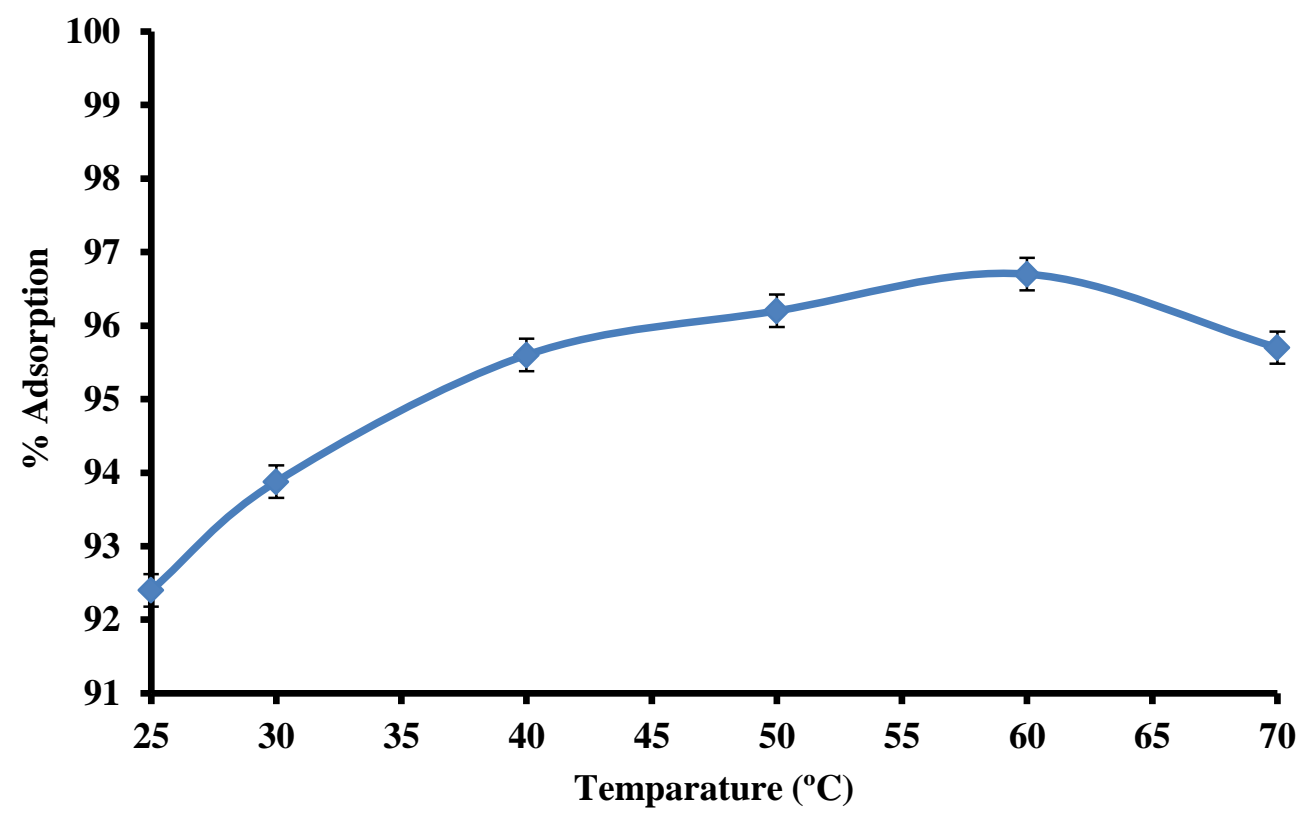

Figure 4: Effect of temperature on \% adsorption of $200 \mathrm{ppm} \mathrm{Pb}$ (II) ions by $0.5 \mathrm{~g}$ of mangrove roots.

It can be seen from Fig. 4 that the $\%$ adsorption at $25^{\circ} \mathrm{C}$ was $92.4 \%$ while at a higher temperature of $60^{\circ} \mathrm{C}$ it was $96.7 \%$. However, at $70^{\circ} \mathrm{C}$ the $\%$ adsorption dropped slightly to $95.7 \%$. This indicates that adsorption process is an endothermic reaction, therefore favored by temperatures above room temperatures.

The increase in metal adsorption with increase in temperature could also be due to dissociation of some compounds available in the adsorbent which may provide more sites for adsorption. Increase in adsorption could also be attributed to increase in number of available active sites or decrease in the boundary layer thickness surrounding the adsorbent.

Adsorption researchers have performed a large number of studies on the effects of temperature on metal uptake. The change in solution temperature affects not only diffusion rate of metal ions but also the solubility of metal ions [24]. Depending on surface functional groups of a given adsorbent, temperature has a given impact on the adsorption capacity. However, it is a common conclusion of many studies that the influence of temperature is to a limited extent and only in a certain temperature range [25]. The adsorption process can be affected by temperature in different ways depending on the exothermic or endothermic nature of the process.

Many researchers have reported that adsorption processes are endothermic in nature. [24] argued that higher temperatures improve the elimination of heavy metals owing to an increase in its surface activity and kinetic energy. In the same way, [26] also observed that the adsorption of $\mathrm{Pb}$ (II) and $\mathrm{Cd}$ (II) by the stalk sponge of maize increased 1.1-1.8 times with increasing temperature from 20 to $40^{\circ} \mathrm{C}$. [27] reported similar observation in case of adsorption of $\mathrm{Cu}$ (II) by watermelon shell

In contrast, [28] found that the adsorption of Cd (II) by cashew nut shell decreased from $80.13 \%$ to $74.32 \%$ with the rise in temperature from $30^{\circ} \mathrm{C}$ to $60^{\circ} \mathrm{C}$. They attributed this to the decrease in surface activity of adsorbent. Similar trend was noticed by [29] in case of $\mathrm{Zn}$ (II), Cd (II) and Mn (II) adsorption onto maize stalks. The adsorption percentage decreased from $52 \%$ to $28 \%$ for $\mathrm{Zn}$ (II) ions, from $34 \%$ to $16 \%$ for Cd (II) ions and from $39 \%$ to $13 \%$ for $\mathrm{Mn}$ (II) ions as the temperature increased from 25 to $55^{\circ} \mathrm{C}$. The authors explained this trend by the damage of active adsorption sites of adsorbents or increasing number of metal ions escaped from the adsorbents surface to the solution. The same behavior can be detected in a research performed by [30] sequestering $\mathrm{Cu}$ (II) and $\mathrm{Zn}$ (II) ions by Citrus reticulate.

\subsection{Effect of $\mathrm{pH}$ on adsorption of $\mathrm{Pb}$ (II) ions}

The $\mathrm{pH}$ of aqueous solutions is an important controlling parameter in the adsorption process. In order to study the effect of $\mathrm{pH}$ on $\mathrm{Pb}$ (II) adsorption onto mangrove roots, the $\mathrm{pH}$ of solution was varied from $2.0-$ 8.0. 


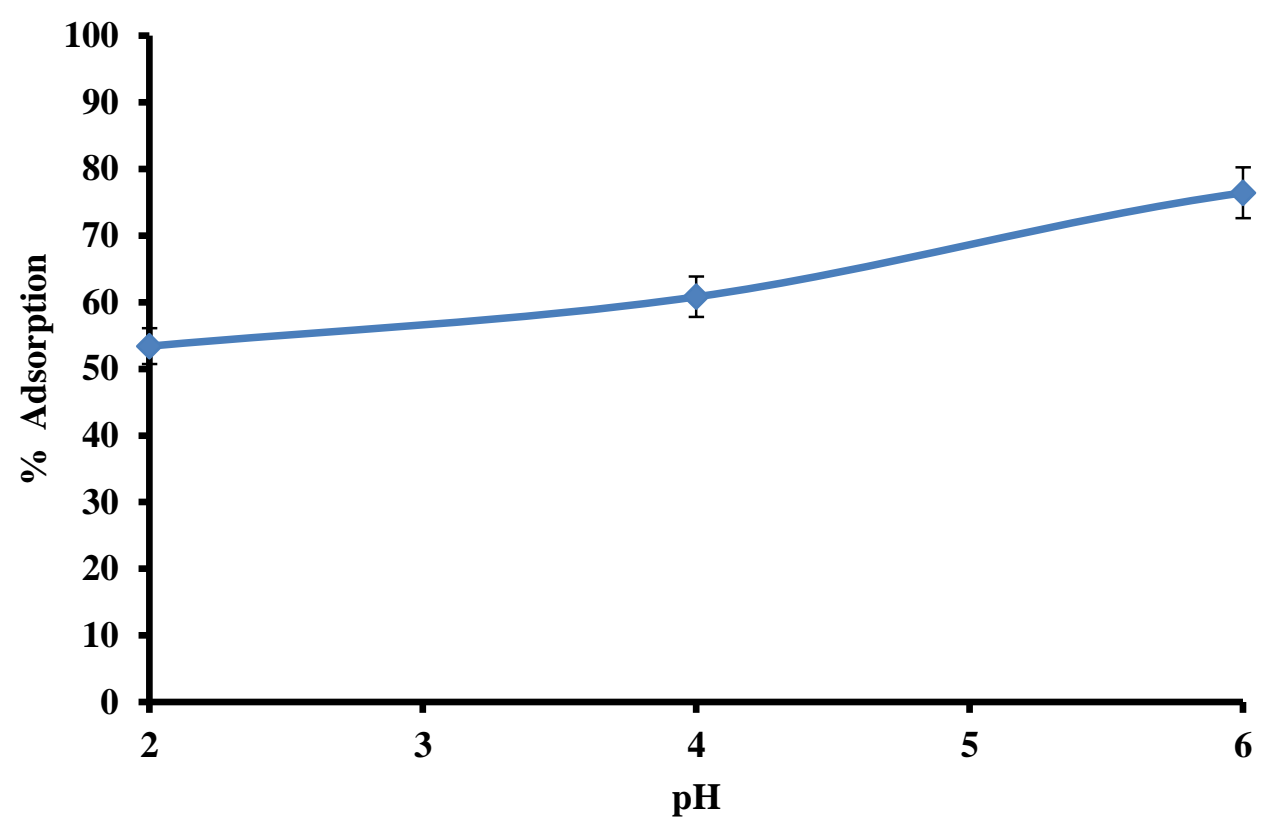

Figure 5: Effect of $\mathrm{pH}$ on \% adsorption of $50 \mathrm{ppm} \mathrm{Pb}$ (II) ions on $0.5 \mathrm{~g}$ mangrove roots.

From Fig. 5, it is observed that the adsorption of $\mathrm{Pb}$ (II) varies with $\mathrm{pH}$. There was a gradual increase in $\mathrm{Pb}$ (II) uptake as the $\mathrm{pH}$ value increased from 2.0 to 8.0. The \% adsorption was minimum (53.4) at $\mathrm{pH} 2.0$. This was because the $\mathrm{H}_{3} \mathrm{O}^{+}$ions were competing with the metal ions for the exchangeable sites on the mangrove roots. The $\mathrm{H}_{3} \mathrm{O}^{+}$ions were preferentially adsorbed rather than the lead ions. At higher $\mathrm{pH}$ values, the numbers of $\mathrm{H}^{+}$ions were few hence the surface was negatively charged. Consequently, the attraction of the cations was enhanced. However, when the $\mathrm{pH}$ was increased above 6.0 , the $\mathrm{Pb}$ (II) ions get precipitated due to the hydroxyl ion forming insoluble lead hydroxide precipitate [31]. Metal speciation in solution is also $\mathrm{pH}$ dependent. The results suggest that at $\mathrm{pH}$ below 7.0 the predominant species are positively charged metal ions. At $\mathrm{pH}$ values higher than 7.0 insoluble hydroxides are formed. Similar results were reported in the literature [3] This implies that the optimal conditions for adsorption of $\mathrm{Pb}$ (II) ions onto mangrove roots are weakly acidic conditions.

[32] demonstrated that the optimum $\mathrm{pH}$ for the adsorption of $\mathrm{Cu}$ and $\mathrm{Pb}$ were about 5 which was rather acidic. At low $\mathrm{pH}(<3)$, there was excessive protonation of the active sites at mangrove roots surface and this often reduces the formation of links between metal ion and the active site. At moderate $\mathrm{pH}$ values (3-6), linked $\mathrm{H}^{+}$is released from the active sites and adsorbed amount of metal ions is generally found to increase. At higher $\mathrm{pH}$ values (> 6), the precipitation is dominant or both ion exchange and aqueous metal hydroxide formation (not necessarily precipitation) may become significant mechanisms in the metal removal process. This condition is often not desirable as the metal precipitation could lead to a misunderstanding for the adsorption capacity. Consequently, in practice metal precipitation is generally not a stabilized form of heavy metal as the precipitation can sometime be very small in size, and upon the neutralization of the effluent from the wastewater treatment plant, the solubility of the metals increases resulting in a re-contamination of the waste outlet stream.

\subsection{Adsorption isotherm studies for Pb (II) ions.}

$\mathrm{The} \mathrm{Pb}$ (II) ions uptake capacity of mangrove roots was evaluated using different concentrations of the metal ions on a fixed mass of adsorbent. Figs 6 and 7 below illustrate the results obtained and the constants calculated. 


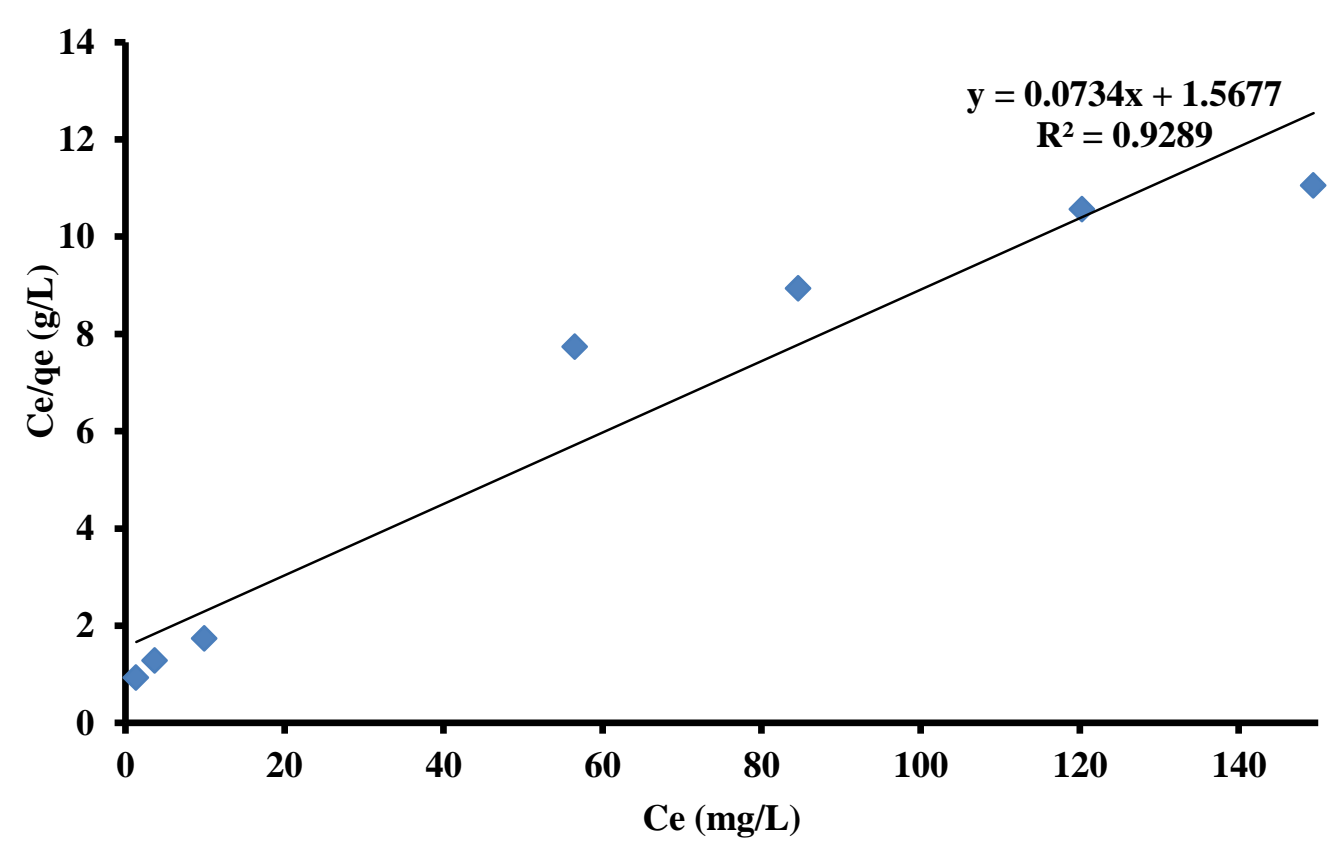

Figure 6: Linearized Langmuir isotherm for adsorption of $\mathrm{Pb}$ (II) ions by $1.0 \mathrm{~g}$ mangrove roots.

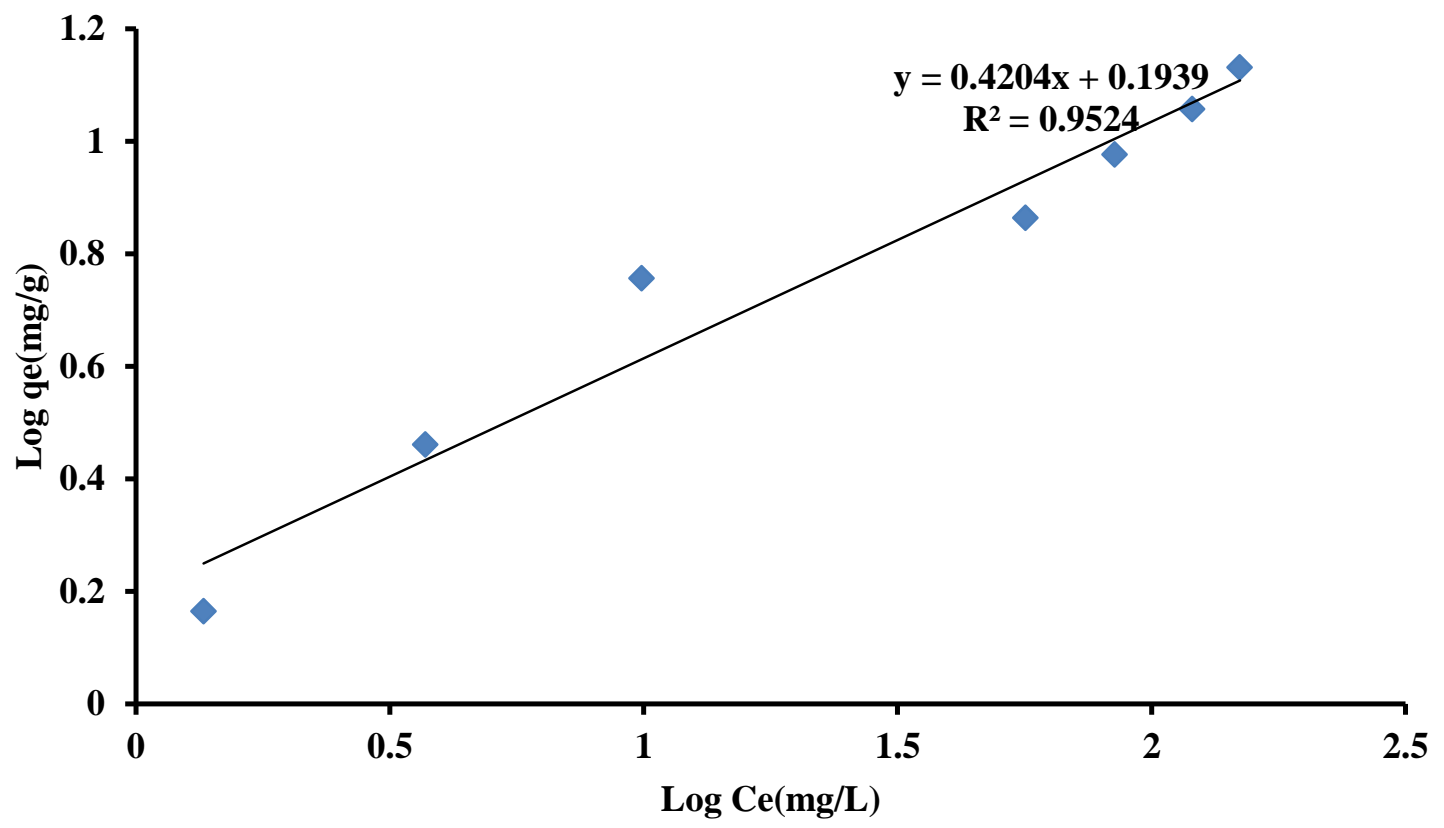

Figure 7: Freundlich isotherm plot for the adsorption of $\mathrm{Pb}$ (II) onto $1.0 \mathrm{~g}$ mangrove roots.

Table 1: Langmuir and Freundlich Isotherm Constants and their Correlation Coefficients for $\mathrm{Pb}$ (II) ions Adsorption using $0.5 \mathrm{~g}$ Mangrove Roots.

\begin{tabular}{|l|l|l|l|l|l|}
\hline \multicolumn{5}{|l|}{ Langmuir } & Freundlich \\
\hline $\mathrm{Q}_{\max }(\mathrm{mg} / \mathrm{L})$ & $b(\mathrm{~L} / \mathrm{mg})$ & $\mathrm{R}^{2}$ & $\mathrm{~K}_{\mathrm{F}}(\mathrm{mg} / \mathrm{g})$ & $n$ & $\mathrm{R}^{2}$ \\
\hline 13.698 & 0.047 & 0.928 & 1.56 & 2.381 & 0.952 \\
\hline
\end{tabular}

The correlation coefficient $\left(\mathrm{R}^{2}\right)$ was found to be 0.952 for $\mathrm{Pb}$ (II) adsorption using Freundlich model. The high value indicated that the equilibrium data fitted well to the Freundlich model, which means that adsorption of the metal ions onto the mangrove roots took place at the binding sites on the surface of the biomass by multilayer adsorption. 
The adsorption capacity was found to be $1.56 \mathrm{mg}$ of $\mathrm{Pb}$ (II) per gram of the adsorbent material. The value of $n$ was found to be 2.381 which mean that the value of $1 / \mathrm{n}$ is in the range of 0 to 1 which indicates favorable adsorption under the conditions of study.

\subsection{Adsorption kinetics of $\mathrm{Pb}$ (II) ions}

Adsorption kinetics involves the search for a best model that well represents the experimental data. In this study, the adsorption equilibrium data were analyzed using pseudo-first-order and pseudo-second-order models. The prediction of adsorption rate gives important information for designing batch adsorption systems. Fig. 8 shows the plot between amounts adsorbed, $Q_{t}(\mathrm{mg} / \mathrm{g})$ versus time $\mathrm{t}(\mathrm{min})$ for different initial concentrations.

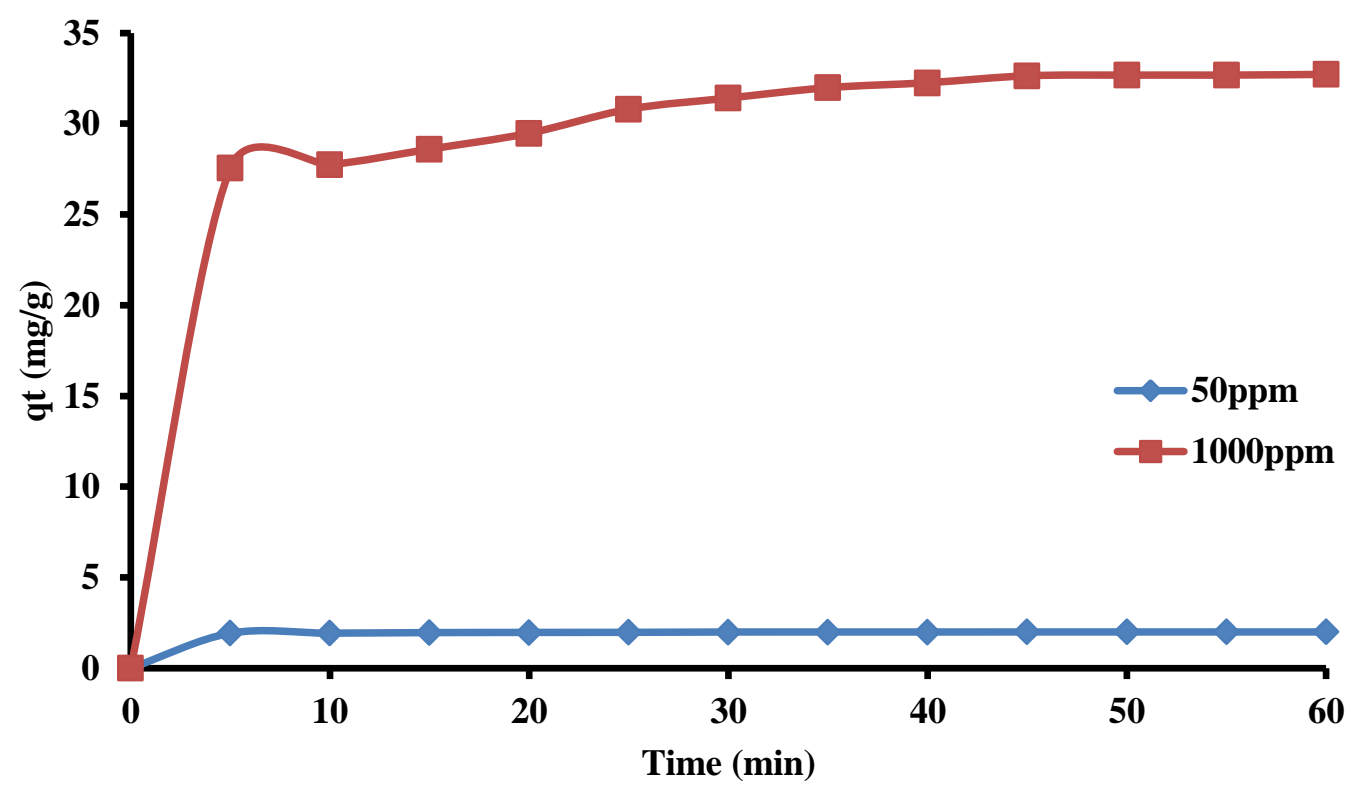

Figure 8: Effect of contact time on uptake of $\mathrm{Pb}$ (II) ions by mangroves roots.

It is evident that metal ions adsorption increased insignificantly as equilibrium was reached. The adsorption at the initial stage could be explained by the availability of a number of vacant active sites on the adsorbent surface. Thus, metal ions accumulated on the adsorbent surface rapidly within the first 5 minutes. In the later stage, adsorption was an attachment controlled process due to less available sorption sites. 


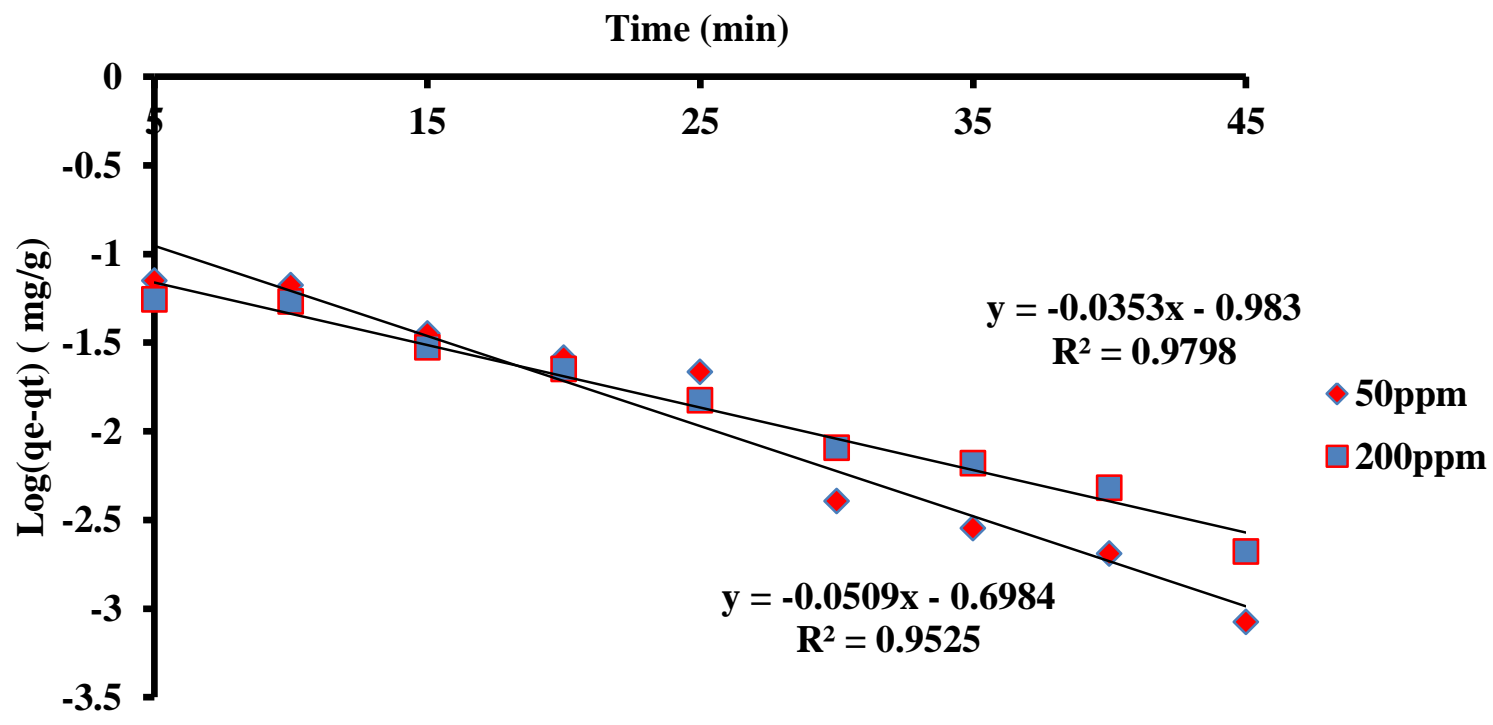

Figure 9: Pseudo-first order plot of $\mathrm{Pb}$ (II) adsorption onto $0.5 \mathrm{~g}$ mangrove roots

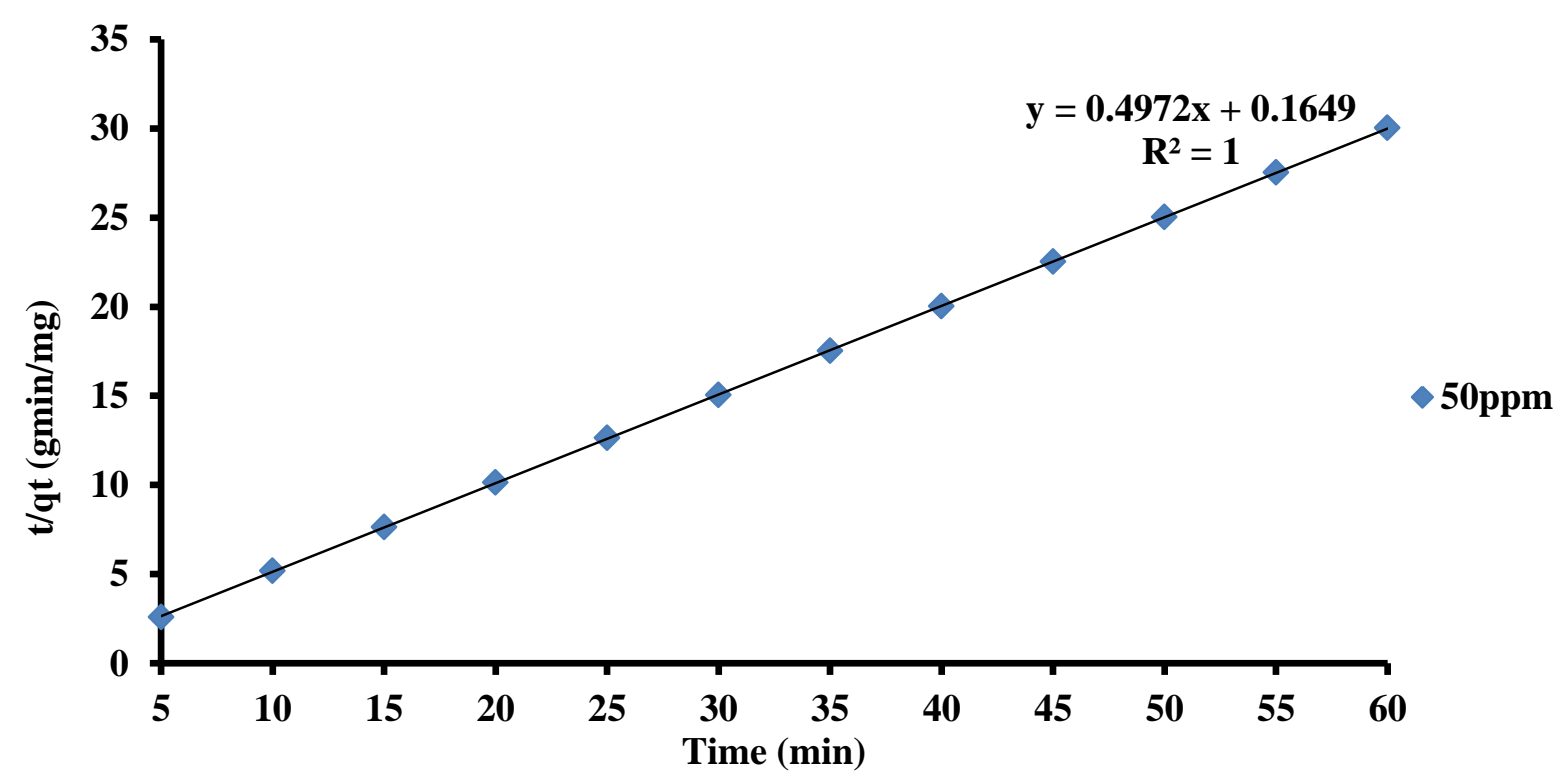

Figure 10: Pseudo-second-order plots for $50 \mathrm{ppm} \mathrm{Pb}$ (II) ions by $0.5 \mathrm{~g}$ mangrove roots. 


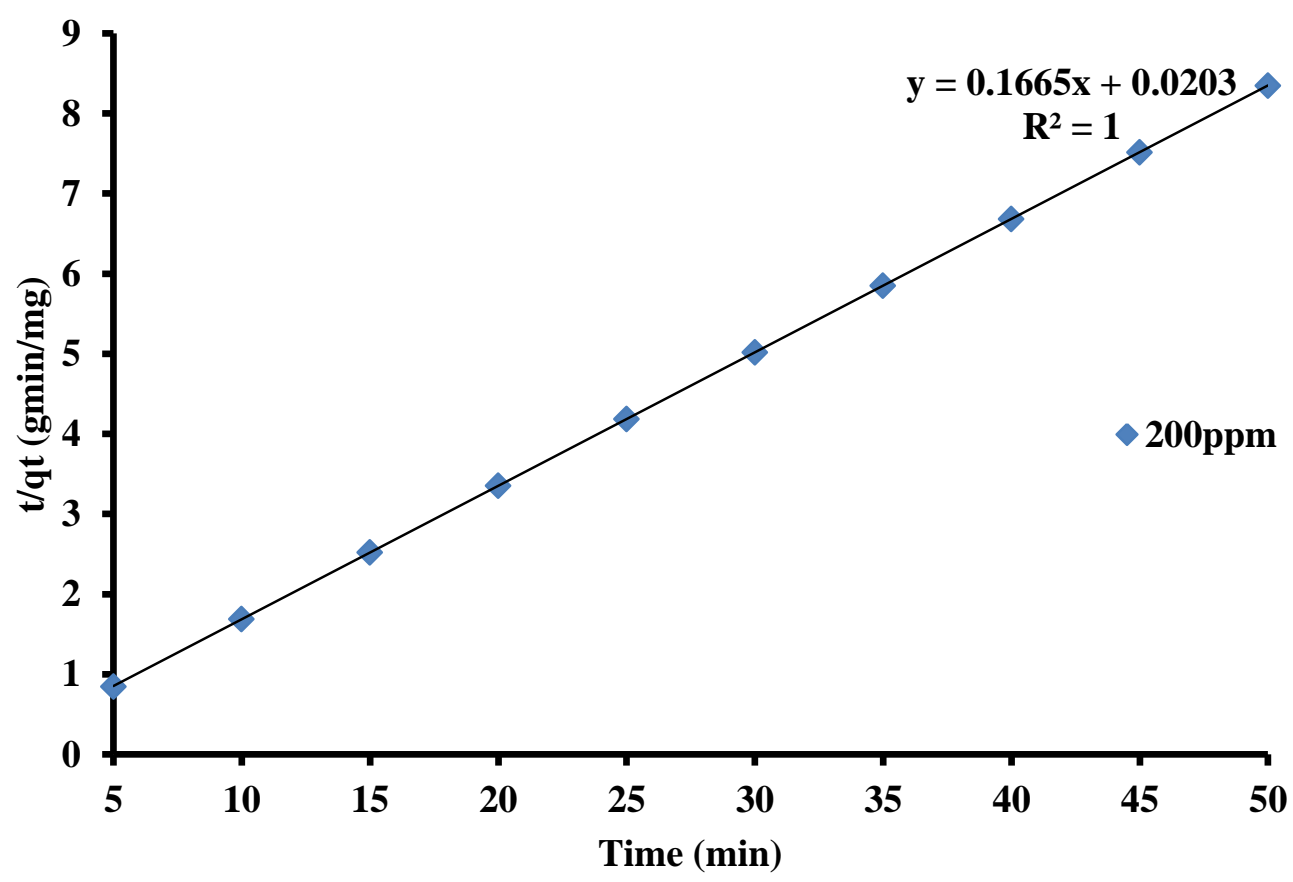

Figure 11: Pseudo-second-order plots for $200 \mathrm{ppm} \mathrm{Pb}$ (II) ions by $0.5 \mathrm{~g}$ mangrove roots.

The pseudo first-order and pseudo second- order model equations were applied to the adsorption data. The results of Figs. 9, 10 and 11 are summarized in Table 2. The conformity between experimental data and the model predicted values were expressed by the correlation coefficients $R^{2}\left(R^{2}\right.$ values close or equal to 1$)$. Relatively high $\mathrm{R}^{2}$ values indicated that the model successfully described the adsorption kinetics. The $\mathrm{R}^{2}$ value of pseudo second-order was higher compared to $\mathrm{R}^{2}$ value of pseudo first order mode.

Table 2: Comparison of Pseudo-First-Order and Pseudo-Second Order at Different Pb (II) ions Concentrations

\begin{tabular}{|l|l|l|l|l|l|l|}
\hline \multicolumn{3}{|c|}{ Pseudo-first order } & \multicolumn{3}{c|}{ Pseudo-second order } \\
\hline$[\mathrm{Pb}] \mathrm{mg} / \mathrm{L}$ & $\mathrm{Q}_{\mathrm{e}}(\mathrm{mg} / \mathrm{g})$ & $\begin{array}{c}\text { constant } \\
\left(\mathrm{min}^{-1}\right)\end{array}$ & $\mathrm{R}^{2}$ & $\begin{array}{l}\mathrm{Q}_{\mathrm{e}} \\
(\mathrm{Mg} / \mathrm{g})\end{array}$ & $\begin{array}{c}\text { constant } \\
\left(\mathrm{min}^{-1}\right)\end{array}$ & $\mathrm{R}^{2}$ \\
\hline 50 & 0.104 & 0.0806 & 0.936 & 2.012 & 1.506 & 1 \\
\hline 200 & 0.2004 & 0.115 & 0.981 & 6.024 & 1.377 & 1 \\
\hline
\end{tabular}

These findings revealed that the pseudo second-order kinetic model provided a good correlation for the adsorption of $\mathrm{Pb}$ (II) onto mangrove roots compared to pseudo first order kinetic model. Therefore, the data show a good compliance with the pseudo equation which is based with equilibrium chemical adsorption [33]. [34] reported pseudo second -order kinetics for adsorption of heavy metal ions from industrial effluents using activated carbon derived from waste coconut buttons.

\section{Conclusion}

Mangrove roots are environmentally friendly potential adsorbent for lead metal. This work examined the efficiency of mangrove roots in removal of $\mathrm{Pb}$ (II) ions from aqueous environment. The results indicated that several factors such as initial solution concentration, initial biomass concentration, $\mathrm{pH}$, contact time and temperature affect the adsorption process. The physico-chemical characteristics of wastewaters from varying sources can be much more complex compared to the aqueous metal solution used in this study. Because of this, removal of other components of wastewater like pesticides, dyes and microorganisms should be studied. In addition, modification of mangrove roots should be carried out to increase adsorption capacity, prevent elution of organic components that stains water and also to increase selectivity in case of wastewater. However, this work can be considered as a preliminary study to conclude that mangrove roots biomass is suitable and efficient material for the adsorption of $\mathrm{Pb}^{2+}$ ions from aqueous solution. The experimental results fitted well with the adsorption isotherm models.

\section{Acknowledgement}

My gratitude goes to the World Federation of Scientists (WFS) through ICIPE for provision of scholarship to facilitate this research work. 


\section{References}

[1]. T. K. Sen, Agricultural By-Product Biomass for Removal of Pollutants from Aqueous Solution by Adsorption, Journal of Environmental Research and Development 6 (3), 2012, 523-533.

[2]. N. A, Khan, S. Ibrahim, and P. Subramaniam, Elimination of Heavy Metals from Wastewater Using Agricultural Wastes as Adsorbents, Malaysian Journal of Science 23, 2004, $43-51$.

[3]. J. Aravind, M. Shanmugaprakash, H. S. Sangeetha, C. Lenin. And P. Kanmani, P. Pigeon Pea (Cajanus cajan) Pod as a Novel EcoFriendly Biosorbent, A Study on Equilibrium and Kinetics of Ni (II) Biosorption, International Journal of Industrial Chemistry, 4, 2013, 1-25.

[4]. D. A. Amboga, J. M. Onyari, P. M. Shiundu, and J. W. Gichuki, Equilibrium and Kinetics Studies for the Biosorption of Aqueous Cd (II) ions onto Eichhornia crassipes Biomass, IOSR-Journal of Applied Chemistry, 7, (1), 2014, 29-37.

[5]. L. M. Mataka, M. T. Henry, R. L. Masamba, and S. M. Sajidu, Lead Remediation of Contaminated Water using Moringa Stenopetala and Moringa Oleifera Seed Powder, International Journal of Environmental Science and Technology, 3 (2), 2006, 131139.

[6]. V. A.Wirnkor, B. O. Amonia. and V. E Ngozi, Batch and Column Adsorption of BOD and COD in Vegetable Oil Industry Effluents using Activated Carbon from Fluted Pumpkin (Telfairia, Occidentalis) Seed Shell, International Letters of Chemistry, Physics and Astronomy, 39, 2014, 4-7.

[7]. R.W. Kimani, B.M. Mwangi, and C.M. Gichuki, Treatment of Flower Farm Wastewater Effluents using Constructed Wetlands in Lake Naivasha, Kenya, Indian Journal of Science and Technology, 5 (1), 2012, 1870-1872.

[8]. V. C. Renge, S. V. Khedkar, and S. V. Pande, Removal of Heavy Metals from Wastewater using Low Cost Adsorbents: A Review, Scientific Reviews and Chemical Communications, 2(4), 2012, 580-584.

[9]. M. E. Argun, S. Dursun, C. Ozdemir, and M. Karatas, Heavy metal adsorption by modified oak sawdust: Thermodynamics and kinetics. Journal of Hazardous Materials, 141, 2006,77-85.

[10]. K. Kathiresan, and B. L. Bingham, Biology of Mangroves and Mangrove Ecosystem, Advances in Marine Biology,40, 2001 81251.

[11]. S. Naskar, and P. K Palit, Anatomy and Physiological Adaptations of Mangroves, Wetland Ecology Management. 23, 2015, 357370 .

[12]. D. Chakraborty, S. Bhar, J. Majumdar, and S. C. Santra, Heavy Metal Pollution and Phytoremediation Potential of Aviccenia Officinalis in the Southern Coast of The Hoogly Estuarine System, International Journal of Environmental Science, 3(6), 2013 2292-2299.

[13]. K. Vijaya, and V. S Yun, Bacterial Biosorbents and Biosorption. Biotechnology Advances, 26, 2008, $266-291$.

[14]. L. S. Guinesi, and E. T. G. Cavalheiro, Influence of Some Reactional Parameters on the Substitution Degree of Biopolymeric Schiff Bases Prepared from Chitosan and Salicylaldehyde. Carbohydrate Polymer, 65, 2006, 557-561.

[15]. M. Jane, A. K. Misihairabgiol, and A. Peter, Adsorption of Heavy Metals by Agro Forestry Waste Derived Activated Carbons Applied to Aqueous Solutions. African Journal of Biotechnology 13 (14), 2014, 1579-1587.

[16]. I. Nhapi, N. Banadda, C. B. Murenzi, U. G Wali, Removal of Heavy Metals from Industrial Waste Water using Rice Husks, Journal of Environmental Engineering 4, 2011, 170-180.

[17]. A. Ahmad, M. Rafatullah, O. Sulaiman, M. H Ibrahim, Y. Y Chii, and B. M. Siddique, Removal of Cu (II) and Pb (II) Ions from Aqueous Solutions by Adsorption onto Sawdust of Meranti wood, Desalination, 247, 2009, 365-646.

[18]. N. Suhada, M.Tahiruddin, S. Zubaidah, A. Rahman, Adsorption of Lead in Aqueous Solution by a Mixture of Activated Charcoal and Peanut Shell, World Journal of Science and Technology Research, 1 (5), 2013, 102-109.

[19]. N. Ahalya, R. D. Kanamadi, and T. V Ramachandra, Biosorption of chromium (VI) from Aqueous Solutions by the Husk of Bengal Gram (Cicer arientinum). Journal of Biotechnology 8, 2005, 224-238.

[20]. O.S. Lawal, A. R. Sanni, I. A. Ajayi, and O. O. Rabiu, Equilibrium, Thermodynamics and Kinetic Studies for the Biosorption of Aqueous Lead(II) Ions onto Seed Husk of Calophyllum inophyllum, Journal of Hazardous Materials 177, $2010,829-835$.

[21]. S. Ayub, S.I. Ali, and N. A. Khan, Adsorption Studies on the Low Cost Adsorbent for the Removal of Cr (VI) from Electroplating Wastewater, Environmental Pollution Control Journal 5 (6), 2002, 10-20.

[22]. M. Kobya, E. Demirbas, E. Senturk, and M. Ince, Adsorption of Heavy Metal Ions from Aqueous Solutions by Activated Carbon Prepared from Apricot Stone. Bioresource Technology, 94 (3), 2005, 345-348.

[23]. T. S. Najim, and S. A Yassim, Removal of Cr (VI) from Aqueous Solution using Modified Pomegranate Peel: Equilibrium and Kinetic Studies, Journal of Chemistry, 6 (1), 2009, 129-142.

[24]. D. Park, Y. Yun, and J. M. Park, The Past, Present, and Future Trends of Biosorption, Biotechnology and Bioprocess Engineering 15, 2010, 86-102.

[25]. S. M Sahmoune, K. Louhab, and A. Boukhiar, Advanced Biosorbent Materials for Removal of Chromium from Water and Waste Waters, Environmental Program. Sustaining Energy 30, 2011, 284-293.

[26]. R. B. Garcia, and J. R. Collin, Adsorption Kinetics of Chromium (III) ions onto Agro-Waste Materials. Bio Resource Technology 101, 2010, 8099-8108.

[27]. K. Banerjee, S. T. Ramesh, P. V. Nidheesh, and K. S. Bharathi, A Novel on Agricultural Waste Adsorbent, Watermelon Shell for the Removal of Copper from Aqueous Solutions, Journal on Energy and Environment 3, 2012, $143-156$.

[28]. P. S. Kumar,S. Ramalingam, V. Sathyaselvabala, S. D. Kirupha, A. Murugesan, and S. Sivanesan, Removal of Cd (II) from Aqueous Solution by Agricultural Waste Cashew Nut Shell, Korean Journal of Chemical Engineering 29, 2012, 756-768.

[29]. G. O. Elsayed, H. A. Dessouki, S.S and Ibrahim, Biosorption of Ni (II) and Cd (II) ions from Aqueous Solution onto Rice Straw, Chemical Sciences 32, 2010, 1230-1247.

[30]. R. Boota, H. N. Bhatti, and M. A. Hanif, Removal of Cu (II) and Zn (II) using Lignocellulosic Fiber Derived from Citrus Reticulata (Kinnow) Waste Biomass. Septic Purification Technology 44, 2009, 4000-4022.

[31]. N. Feng, X. Guo, S. Liang, Y. Zhu, and J. Liu, Biosorption of Heavy Metals from Aqueous Solutions by Chemically Modified Orange Peel, Journal on Hazardous Material 185, 2011, 49-54.

[32]. A. Kongsuwan, P. Patnukao, and P. Pavasant, Removal of Metal Ions from Synthetic Waste Water by Activated Carbon from Eucalyptus Camaldulensis Dehn Bark. The $2^{\text {nd }}$ Joint International Conference on Sustainable Energy and Environment, Bangkok, Thailand. 2006.

[33]. T. L. Seey, and N. M. K. Jain, Characterization of Mangrove Bark as a Potentially Low- Cost Adsorbent for Reactive Dye Removal from Aqueous Solutions: Equilibrium, Mechanisms and Kinetics, International Journal of Pure and Applied Sciences 9 (1), 2012, 9-19. 
Efficacy Of Mangrove (Rhizophora Mucronata) Roots Powder For Adsorption Of Lead (II) Ions...

[34]. T. S. Anirudhan, and S. S. Sreekumari, Adsorptive Removal of Heavy Metal Ions from Industrial Effluents using Activated Carbon Derived from Waste Coconut Buttons. Journal of Environmental Sciences, 23 (12), 2011, 1989-1998. 